\title{
Experimental Study on Spring Deformation of Vibration Isolation Turbine-generator Foundation under Horizontal Earthquake
}

\author{
Dong $\mathrm{An}^{1, \mathrm{a}^{*}}$ and Tiejun $\mathrm{Qu}^{1, \mathrm{~b}}$ \\ ${ }^{1}$ North China University of Technology, Beijing, China \\ ahadesloveln@163.com, bqutiejun18@163.com
}

Keywords: Spring deformation; Turbine-generator foundation; Spring vibration isolating; Horizontal earthquake

\begin{abstract}
The pseudo-dynamic test was conducted on the turbine-generator spring vibration isolation foundation to study the spring deformation under action of horizontal earthquake. The test model is 1:8 according to the similarity relation conversion. By experimental results, the story drift of spring vibration vibrating foundation is under the limit value provided in Code for seismic design of buildings. With the existing of spring vibration isolation, the foundation has good performance in the horizontal earthquake. The displacements of columns are no longer equal because of the spring vibration isolation. The earthquake force is redistributed to the columns so that each one can fully play its role.
\end{abstract}

\section{Introduction}

In the power plant, the turbine-generator set is playing an impotent role. The improvement of technical innovation will bring the design challenges of the turbine frame foundation. Shao [1] first studied a 1:10 model of the spring vibration isolation turbine-generator foundation in China. The pseudo-dynamic test was conducted on 1:8 model of 1251MW turbine-generator foundation, the character of earthquake response is studied [2]. Dynamic characteristic tests were conducted on turbine-generator foundation [3, 4]. Recently, some studies were on the turbine-generator foundation $[5,6]$. For a turbine-generator foundation, the spring isolation is the core equipment; the spring deformation is needed to study for the turbine-generator foundation.

Based on the turbine spring vibration isolation foundation pseudo dynamic seismic test to study the spring deformation under action of horizontal earthquake, the seismic performance evaluation, put forward reasonable suggestions on the basis of structural design.

\section{Test Conditions}

Model Fabricating and Measurement. Based on pseudo-dynamic test [7, 8], the spring deformation of spring vibration isolation turbine-generator foundation is studied under action of horizontal earthquake. The model [9, 10] of turbine-generator foundation scaled 1:8 and the concrete which grade is $\mathrm{C} 40$ and the ratio of reinforcement are same as prototype. The horizontal load is applied by the hydraulic actuator. Test loading system is shown in Fig. 1. The high precision displacement sensors (LVDT) were layout on the structure model to control the displacement of the pseudo dynamic test and measurement plate displacement. All columns and joints between column and platform were layout the displacement measuring points. The base plate is also arranged to measure the displacement in order to monitor it. Arrangement and number of measuring points are shown in Fig. 1. The completion of the test model is shown in Fig. 2. 


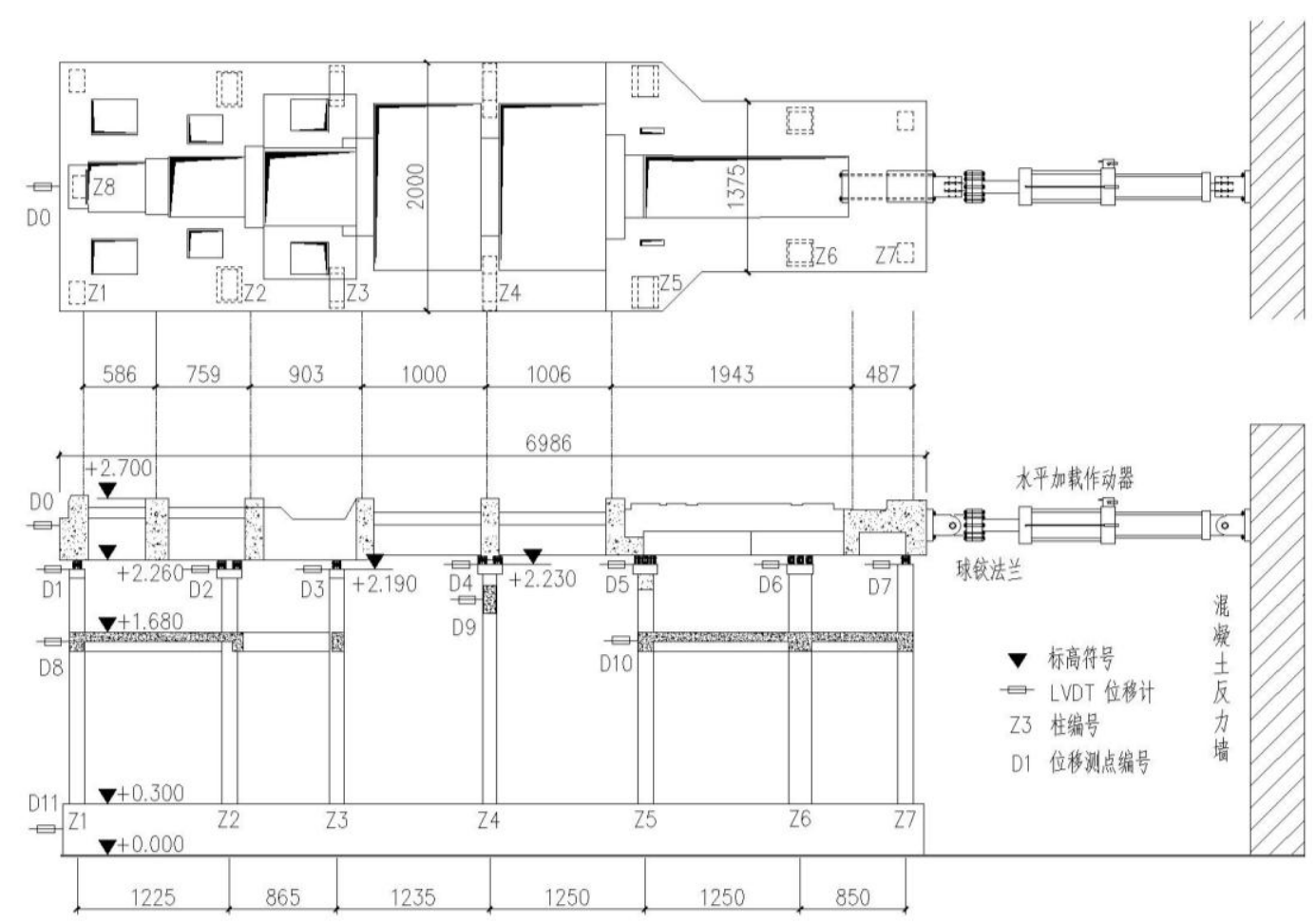

Figure 1. Test loading system and measuring points

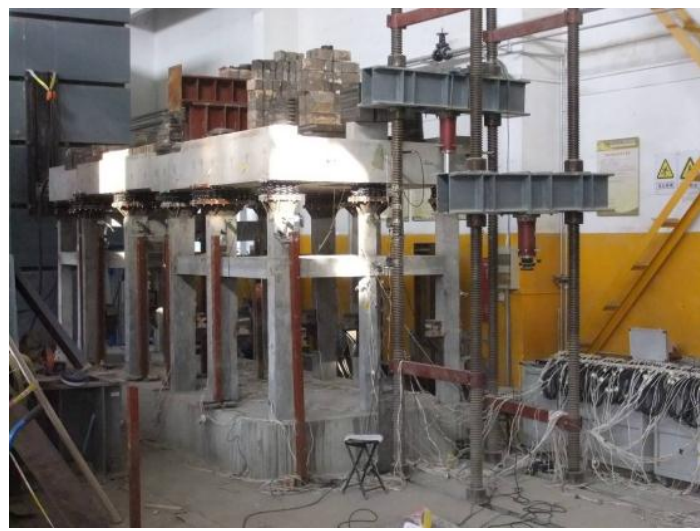

Figure 2. Experimental model

\section{Test Results and Analysis}

Story Drift. Table 1 lists the maximum story drifts of each position. "Code for seismic design of buildings" (GB50011-2010) provides that the elastic limit value of story drifts of reinforced concrete frame is [1/550] when frequently earthquake, and the value is [1/50] when rarely earthquake. So the deformation capacity of spring vibration isolation foundation is in line with China's current seismic design code requirements in the case of frequently and rarely earthquake. Middle platform story drift is less than that of floor displacement, indicating the structural layer displacement concentrates in the middle platform, also is the isolator between the top and the spring plate, spring deformation accounted for a larger proportion of the overall structure deformation. The spring vibration isolation foundation will increase the interlayer displacement angle of the intermediate platform, but the displacement response can be effectively controlled within the allowable range of the specification. 
Table 1. The story drifts of key position

\begin{tabular}{|c|c|c|}
\hline Measurement Position (number) & Frequently & Rarely \\
\hline Table and plate (D0) & $1 / 1307$ & $1 / 138$ \\
\hline Bottom and middle platform of high pressure cylinder side (D8) & $1 / 2851$ & $1 / 593$ \\
\hline Bottom and Z4 beam (D9) & $1 / 1600$ & $1 / 186$ \\
\hline Bottom and middle platform of generator side (D10) & $1 / 2865$ & $1 / 574$ \\
\hline
\end{tabular}

Spring Deformation. The stiffness parameters of the spring vibration isolator used in this experiment are shown in Table 2. The pillars of the horizontal stiffness and stiffness of spring vibration isolator is an average of 2.30 by calculation, except between the low pressure cylinder without intermediate platform column (Z4), the level of the foundation stiffness of isolator stiffness is smaller than the column level. Table 3 gives the maximum deformation displacement of columns and spring under horizontal earthquake; top displacement is less than the platen displacement. From the displacement of 8 columns of each column and the corresponding spring stiffness are different, so the top displacement is different, basically in accordance with the column stiffness is inversely proportional to the distribution. Rigid foundation, plate and column overall casting, is rigid, all have the same displacement at the top of the column, the column stiffness under the maximum internal forces, the most easily damaged. After the foundation of the spring vibration isolator, separation plate and column, is a flexible foundation, displacement of each column is different, just post small displacement of columns, column top displacement stiffness big small, spring makes each column between the earthquake undertakes to redistribute, make the pillars of force uniform, each column can give full play to the role of.

Table 2 Parameters of spring isolation in model $[\mathrm{kN} / \mathrm{mm}]$

\begin{tabular}{|c|c|c|c|c|c|c|c|c|}
\hline Number & Z1 & Z2 & Z3 & Z4 & Z5 & Z6 & Z7 & Z8 \\
\hline Vertical stiffness & 13.31 & 40.69 & 20.50 & 29.33 & 25.43 & 26.66 & 7.13 & 13.31 \\
\hline Horizontal stiffness & 1.99 & 6.01 & 3.14 & 4.40 & 3.75 & 3.94 & 1.08 & 1.99 \\
\hline
\end{tabular}

Table 3 Column Displacement and Spring Deformation [mm]

\begin{tabular}{|c|c|c|c|c|c|c|c|c|c|}
\hline \multicolumn{2}{|c|}{ Number } & $\mathrm{Z} 1$ & Z2 & $\mathrm{Z3}$ & $\mathrm{Z} 4$ & $\mathrm{Z} 5$ & Z6 & $\mathrm{Z7}$ & $\mathrm{Z} 8$ \\
\hline \multirow{5}{*}{ 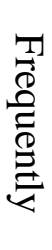 } & Total & 15.21 & 15.21 & 15.21 & 15.21 & 15.21 & 15.21 & 15.21 & 15.21 \\
\hline & Column & 6.73 & 9.33 & 9.3 & 13.31 & 7.79 & 11.12 & 7.54 & 9.61 \\
\hline & Percentage & $44.23 \%$ & $61.31 \%$ & $61.14 \%$ & $87.50 \%$ & $51.20 \%$ & $73.09 \%$ & $49.58 \%$ & $63.15 \%$ \\
\hline & Spring & 8.48 & 5.88 & 5.91 & 1.9 & 7.42 & 4.09 & 7.67 & 5.6 \\
\hline & Percentage & $55.77 \%$ & $38.69 \%$ & $38.86 \%$ & $12.50 \%$ & $48.80 \%$ & $26.91 \%$ & $50.42 \%$ & $36.85 \%$ \\
\hline \multirow{5}{*}{ 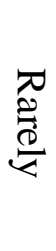 } & Total & 144.34 & 144.34 & 144.34 & 144.34 & 144.34 & 144.34 & 144.34 & 144.34 \\
\hline & Column & 30.55 & 38.94 & 36.2 & 93.95 & 59.11 & 33.65 & 75.08 & 34.73 \\
\hline & Percentage & $21.16 \%$ & $26.98 \%$ & $25.08 \%$ & $65.09 \%$ & $40.95 \%$ & $23.31 \%$ & $52.02 \%$ & $24.06 \%$ \\
\hline & Spring & 113.8 & 105.4 & 108.14 & 50.39 & 85.23 & 110.69 & 69.26 & 109.62 \\
\hline & Percentage & $78.84 \%$ & $73.02 \%$ & $74.92 \%$ & $34.91 \%$ & $59.05 \%$ & $76.69 \%$ & $47.98 \%$ & $75.94 \%$ \\
\hline
\end{tabular}

\section{Conclusions}

In this paper, the pseudo-dynamic test of the vibration isolation foundation of the turbine-generator of power plant under 7 degree earthquakes is conducted to study the spring deformation of the foundation under the horizontal earthquake. Under the action of rarely earthquakes, the displacement between different layers of the foundation is less than the limit of elastic-plastic 
inter-story displacement. The deformation capacity of the structure accords with the requirements of current seismic design standard in China. Under the action of horizontal rarely earthquakes, the effect of spring vibration isolator is obvious. The deformation of the spring accounts for a large proportion of the whole displacement of the structure. The displacement of the top of each foundation is no longer equal, the horizontal seismic force of each column is redistributed, and the column can be more fully play a role.

\section{Acknowledgements}

This paper was financially supported by Beijing Natural Science Foundation (8142015).The authors' deeply express sincere appreciation to them.

\section{References}

[1] X.Y. Shao, J.ZH. Zhou, X.J. Yin and T.J. Qu, Research of model test of spring vibration isolated turbogenerator foundation-Pseudo-dynamic earthquake Test [J]. Engineering Journal of Wuhan University, Vol.S1 (2011), 389-392.

[2] T.J. Qu, K. Xiang, X.J. Yin and X.Y. Shao Pseudo-dynamic Test of the Anti-seismic Performance of Turbine Generator Foundation. Earthquake Resistant Engineering and Retrofitting. Vol.01 (2013), 115-119.

[3] L.G. Kang, X.W. Li, Y.L. Xie and G.L. Bai,Du Yanning, Experimental Research and analysis on dynamic characters of turbione-generator unit frame foudation[J]. Journal of Building Structure, Vol.S1 (2008), 20-26.

[4] B.Y. Zhang, Q.H. Li, W. Wang and X.Y. Shao, Experiment study on dynamic characteristics of spring vibration isolating foundation for large turbine-generator set, Journal of Harbin Institute of Techonlogy [J]. Vol.04 (2015), 37-43.

[5] D. An. Experimental Study on Seismic Performance of Spring Turbine -generator Units with Elastic Isolation (MS., North China University of Technology, China 2010), p.28.

[6] M.M. Zan. Research on the horizontal seismic behavior of the vertical vibration damping spring structure (MS., North China University of Technology, China 2015), p.18.

[7] S.A. Mahin, P.-s.B. Shing, Pseudodynamic Method for Seismic Testing, Journal of Structural Engineering, Vol.111 (1985), 1482 1503.

[8] K. Takanashi, M. Nakashima, Japanese Activities on On-Line Testing, Journal of Engineering Mechanics, Vol.113 (1987), 1014 1032.

[9] A.G. Atkins, R.M. Caddell, The laws of similitude and crack propagation, International Journal of Mechanical Sciences, Vol.16 (1974), 541 548.

[10] S. Kumar, Y. Itoh, K. Saizuka, Pseudodynamic Testing of Scaled Models, Journal of Structural Engineering, Vol.123 (1997), 524 526. 